\title{
The Role of Nrf2 and PPAR $\gamma$ in the Improvement of Oxidative Stress in Hypertension and Cardiovascular Diseases
}

\author{
Ima DOVINOVA ${ }^{1,2}$, Miroslava KVANDOVA ${ }^{3}$, Peter BALIS ${ }^{1}$, Linda GRESOVA ${ }^{1}$, Miroslava \\ MAJZUNOVA $^{1,4}$, Lubica HORAKOVA ${ }^{1}$, Julie Y. H. CHAN ${ }^{5}$, Miroslav BARANCIK ${ }^{1}$ \\ ${ }^{1}$ Centre of Experimental Medicine, Slovak Academy Of Sciences, Bratislava, Slovak Republic, \\ ${ }^{2}$ Intitute of Biochemistry and Microbiology, Faculty of Chemical and Food Technology, Slovak \\ University of Technology in Bratislava, Bratislava, Slovak Republic, ${ }^{3}$ Center for Cardiology, \\ Cardiology I, Medical Center of the Johannes Gutenberg-Universität Mainz, Germany, ${ }^{4}$ Department \\ of Animal Physiology and Ethology, Faculty of Natural Sciences, Bratislava, Slovak Republic, \\ ${ }^{5}$ Institute for Translational Research in Biomedicine, Chang Gung Memorial Hospital, Kaohsiung, \\ Taiwan
}

Received October 8, 2020

Accepted December 7, 2020

\begin{abstract}
Summary
Reactive oxygen species are an important element of redox regulation in cells and tissues. During physiological processes, molecules undergo chemical changes caused by reduction and oxidation reactions. Free radicals are involved in interactions with other molecules, leading to oxidative stress. Oxidative stress works two ways depending on the levels of oxidizing agents and products. Excessive action of oxidizing agents damages biomolecules, while a moderate physiological level of oxidative stress (oxidative eustress) is necessary to control life processes through redox signaling required for normal cellular operation. High levels of reactive oxygen species (ROS) mediate pathological changes. Oxidative stress helps to regulate cellular phenotypes in physiological and pathological conditions. Nrf2 (nuclear factor erythroid 2-related factor 2, NFE2L2) transcription factor functions as a target nuclear receptor against oxidative stress and is a key factor in redox regulation in hypertension and cardiovascular disease. Nrf2 mediates transcriptional regulation of a variety of target genes. The Keap1-Nrf2-ARE system regulates many detoxification and antioxidant enzymes in cells after the exposure to reactive oxygen species and electrophiles. Activation of Nrf2/ARE signaling is differentially regulated during acute and chronic stress. Keap1 normally maintains Nrf2 in the cytosol and stimulates its degradation through ubiquitination. During acute oxidative stress, oxidized molecules modify the interaction of Nrf2 and Keap1, when Nrf2 is released from the cytoplasm into the nucleus where it binds
\end{abstract}

to the antioxidant response element (ARE). This triggers the expression of antioxidant and detoxification genes. The consequence of long-term chronic oxidative stress is activation of glycogen synthase kinase $3 \beta$ (GSK-3 $\beta$ ) inhibiting Nrf2 activity and function. PPARY (peroxisome proliferator-activated receptor gamma) is a nuclear receptor playing an important role in the management of cardiovascular diseases, hypertension and metabolic syndrome. PPARy targeting of genes with peroxisome proliferator response element (PPRE) has led to the identification of several genes involved in lipid metabolism or oxidative stress. PPARy stimulation is triggered by endogenous and exogenous ligands - agonists and it is involved in the activation of several cellular signaling pathways involved in oxidative stress response, such as the PI3K/Akt/NOS pathway. Nrf2 and PPARy are linked together with their several activators and Nrf2/ARE and PPARY/PPRE pathways can control several types of diseases.

\section{Key words}

Nrf2 - PPARy - Oxidative stress - Redox regulation • Hypertension • Cardiovascular diseases

\section{Corresponding author}

I. Dovinova, Institute of Normal and Pathological Physiology, Centre of Experimental Medicine, Slovak Academy of Sciences, Dubravska cesta 9, 84104 Bratislava, Slovak Republic. E-mail: ima.dovinova@savba.sk 
Oxidative stress and redox status in physiological and pathological processes

Oxidative stress works two ways depending on the levels of oxidizing agents and products. The doubleedged tool of oxidative stress helps to regulate cellular phenotypes in physiological and pathological conditions. Maintenance of homeostasis requires a low level of oxidants - the oxidative eustress - that is essential for the control of life processes by means of redox signaling (Sies et al. 2017). High production of reactive oxygen species (ROS) is associated with induction of apoptosis and/or necrosis, while lower ROS levels are associated with activation of a transcription factor - nuclear factor erythroid 2-related factor 2 (Nrf2). Radical formation is modified by antioxidant and detoxification responses (Majzunova et al. 2013). Oxidative stress has both physiological and pathophysiological manifestations. A massive increase of ROS concentrations causes damage of biomolecules (lipids, proteins and DNA) and has been linked to a variety of pathologies. On the other hand, ROS produced by moderate oxidative stress take part in the activation of intracellular signaling pathways important for normal physiological functions (Schieber and Chandel 2014).

The redox status could be defined as the balance between oxidants and antioxidants, where oxidants include intracellularly produced free radicals and other reactive oxygen species. ROS are byproducts of aerobic metabolism and they are predominantly produced by NADPH oxidases, mitochondria, xanthine oxidase, and uncoupled endothelial nitric oxide synthase (uncoupled eNOS) (Touyz 2005). Physiologically, they are produced in controlled manner and play an important role in cell signaling (Schieber and Chandel 2014). ROS are free radicals, are highly reactive and can attack biomacromolecules. That could lead to a change or a loss of their physiological functions (changed protein-protein interaction, modulation of gene expression via nuclear factor activation/deactivation, etc.). ROS include superoxide anion $\left(\mathrm{O}_{2}{ }^{\circ}\right)$, hydrogen peroxide $\left(\mathrm{H}_{2} \mathrm{O}_{2}\right)$, and hydroxyl radicals $\left({ }^{\circ} \mathrm{OH}\right)$, perhydroxyl radical $\left(\mathrm{HOO}^{\circ}\right)$, alkoxyl radical (RO'), and peroxyl radical (ROO) (Wang and Jiao 2000).

In normal cellular metabolism, ROS are produced by various sources in different cellular compartments. In equilibrium state of ROS, physiological state of the cells is maintained without disturbing the physiological homeostasis (oxidative eustress). Normal metabolism and functions maintaining steady state require a low level of oxidants that is essential for the control of life processes by means of redox signaling (Sies et al. 2017). Oxidative stress could be generated endogenously (cell metabolism) and exogenously (exposome). In oxidative distress, excess ROS create pathophysiological alterations in cells (such as damage of membrane biomolecules and DNA) and can contribute to disease development (Sies and Jones 2020). Oxidative stress mediated by increased ROS production induces imbalance of redox pathways followed by oxidative damage. This is a key factor in the pathophysiology of several acute and chronic diseases. In particular, pathophysiological manifestations of cardiovascular diseases (such as hypertension, heart failure, atherosclerosis, cardiac hypertrophy, diabetes, etc.) are triggered by oxidative stress (Dovinova et al. 2015a). In hypertension, increased neurohumoral stimulation of the renin-angiotensin system leads, through binding of angiotensin II on the $\mathrm{AT}_{1}$ receptor, to the stimulation of NADPH oxidase. High ROS production is associated with induction of apoptosis and/or necrosis, while lower ROS levels induce activation of the Nrf2 transcription factor pathway modified by antioxidant and detoxication response (Majzunova et al. 2013).

The renin-angiotensin system, production of ROS, nitric oxide synthase and superoxide dismutase are associated with the development or improvement of hypertension and cardiovascular diseases

The renin-angiotensin system (RAS)

Intracellular signaling pathways work in several active organs such as liver, kidney, lungs, hypothalamus or heart. Individual proteins of the RAS signaling pathway are expressed in several tissues: angiotensinogen is produced in the liver while renin is produced in the kidney. Angiotensin I (AngI) is converted to angiotensin II (AngII) in the lungs, vessels and heart under the catalytic action of the angiotensin-converting enzyme (ACE). AngII activates the cell membrane $\mathrm{AT}_{1}$ receptor (AT1R) which, through the G-protein, activates NADPH oxidase, which in turn increases ROS production and vasoconstriction. In ACE2 activation, AngII can activate the $\mathrm{AT}_{2}$ receptor (AT2R) with ensuing effects on NO synthase, vasodilatation and ROS decrease. Reactive oxygen species and changes in radical production can break down redox-sensitive signaling and play 
an important role in the development of cardiovascular diseases and hypertension (Fig. 1).

Activation of circulating and local RAS components is involved in the cardiovascular disorders associated with systolic and diastolic myocardial dysfunction. Increased RAS activation and AngII production leads to an imbalance of redox pathways and to the activation of ROS-producing sources (Majzunova et al. 2017, $\mathrm{Wu}$ et al. 2014, Dovinova et al. 2013). Increased ROS production in the liver, kidney and the heart can be a result of several conditions leading to excess activation of NADPH oxidase and can lead to cardiovascular disease and hypertension. On the other hand, AngII could activate AngII receptor type 2 (AT2R). This activation acts against AT1R and plays an important role especially in the prenatal period, when AT2R activation has antiproliferatory effect and could result in increased expression and/or activation of NOS (Kvandova et al. 2016).

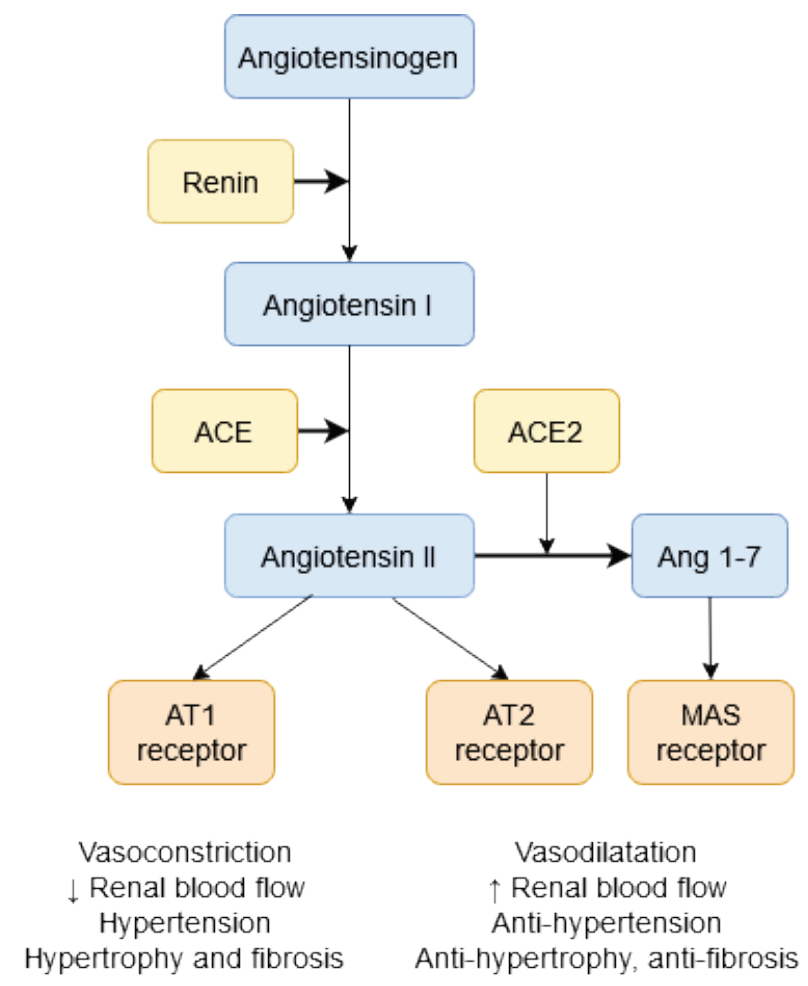

Fig. 1. The renin-angiotensin system in cardiovascular diseases and hypertension.

ROS production, NOS and SOD protein expression and enzyme activities

The activation of angiotensin II (AngII) receptor type 1 (AT1R) by binding of AngII leads to the stimulation of NADPH oxidase, which results in increased ROS production that follows the $G$ proteincoupled receptor (GPCR) activation (Ushio-Fukai 2009). Many enzyme systems, including among others the NADPH oxidase, mitochondrial respiratory chain, and uncoupled nitric oxide synthase, have the potential to generate reactive oxygen species. ROS activate PI3K/Akt signaling via oxidation and phosphorylation, which is a negative regulator of PI3K signaling (Wu et al. 2013).

The therapy of hypertension and cardiovascular disease can include modulation of antioxidant responses by (i) modulation of NO bioavailability through administration of NO; (ii) stimulation of NOS activities by agonists or by the NOS gene incorporation; (iii) scavenging of ROS such as superoxide; or (iv) activation of antioxidant gene expression (Dovinova et al. 2009). Body NO is replenished from exogenous sources because diet is important for the nitrate/nitrite supply, and from endogenous cellular sources due to enzymatic NO production by the various nitric oxide synthases (NOS) using oxygen and L-arginine as substrates, and the co-factor $\mathrm{BH}_{4}$. Two isoforms of NOS, the endothelial NOS (eNOS, NOS3) and the neuronal NOS (nNOS, NOS1), are present in the healthy heart. When $\mathrm{BH}_{4}$ levels are reduced, the catalytic activity leads to NOS uncoupling and the reaction of NO with superoxide to produce peroxynitrite $\left(\mathrm{ONOO}^{-}\right)$(Crabtree and Channon 2011, Andreadou et al. 2020).

The activated phosphorylation pathways (PI3K/Akt) activate transcription factors such as the nuclear factor kappa B $(\mathrm{NF}-\kappa \mathrm{B})$ and the Nrf2, which stimulate transcription of genes after moving into the nucleus. Activation of the transcription NF- $\kappa \mathrm{B}$ signaling pathway may be associated with the development of cardiac hypertrophy, heart failure and hypertension. Proteins encoded by these target genes in turn mediate cellular consequences leading to changes in the phenotypes, such as hypertrophy, inflammation or hypertension. Activation of $\mathrm{Nrf} 2$ stimulates the production of antioxidants involved in antioxidant defense (Balakumar and Jagadeesh 2010, Finkel 2011) (Fig. 2).

Superoxide dismutases (cytosolic SOD1, mitochondrial SOD2, and extracellular SOD3) are ubiquitous enzymes that operate in the presence of ROS. They catalyze the conversion of superoxide into oxygen and hydrogen peroxide. Superoxide anions are the intended product of dedicated signaling enzymes as well as the byproduct of several metabolic processes including mitochondrial respiration. Through their activity, SOD 
enzymes control the levels of a variety of reactive oxygen and nitrogen species, thus limiting both the potential toxicity of these molecules and controlling broad aspects of cellular life that are regulated by their signaling functions. All aerobic organisms have multiple SOD forms occupying different cellular and subcellular locations, reflecting the slow diffusion and multiple sources of their substrate - superoxide. This compartmentalization also points to the need for fine local control of ROS signaling and to the possibility for ROS to signal between compartments (Wang et al. 2018).

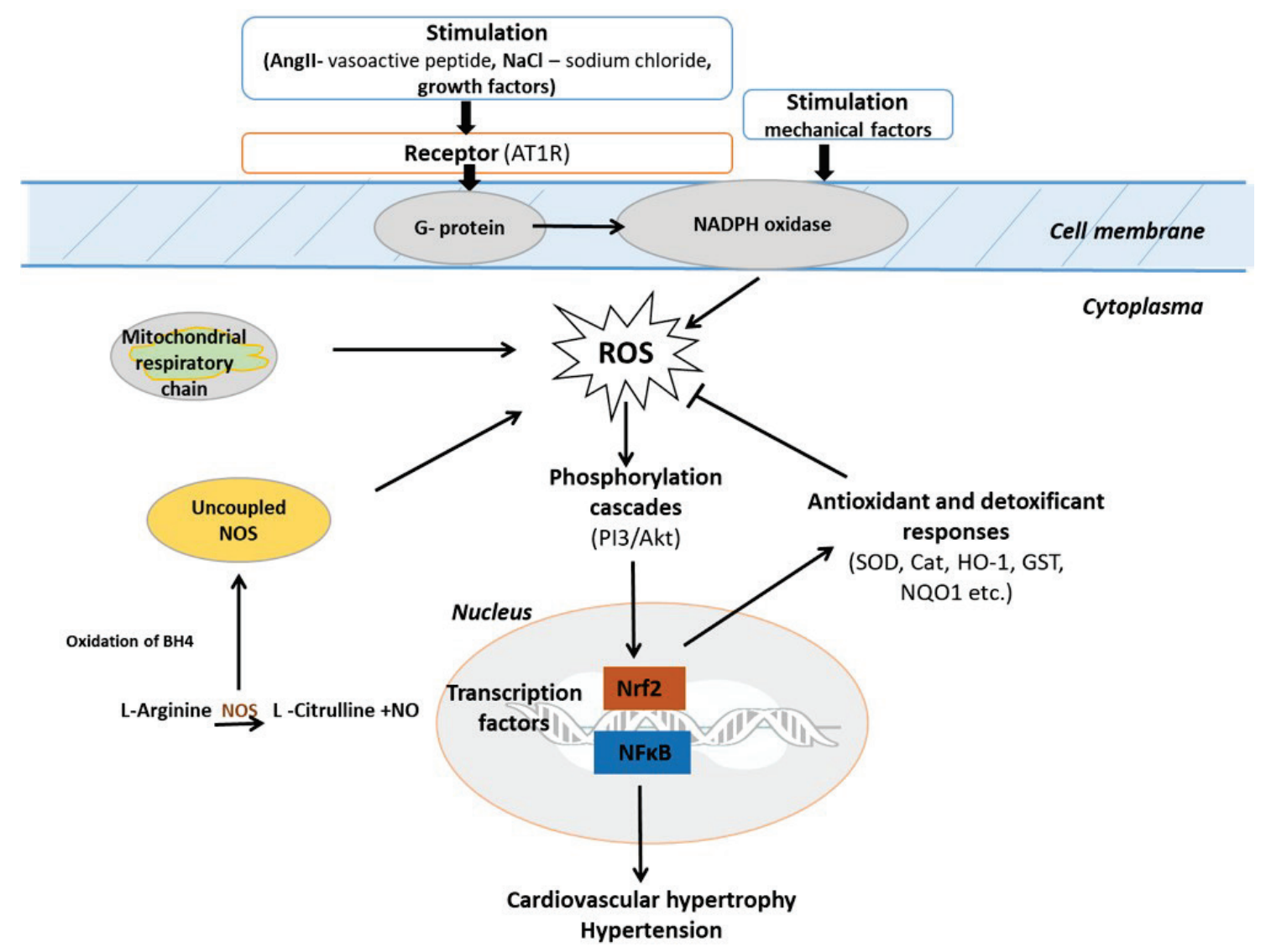

Fig. 2. Redox signaling in cardiovascular diseases and hypertension: neutralization of ROS by Nrf2 antioxidant response.

\section{Nrf2 and PPAR $\gamma$ effects and activation in cardiovascular diseases and hypertension}

An important role in cardiovascular damage is played by oxidative stress triggered by an increase in ROS levels. ROS production is strictly regulated. Organisms defend against oxidative stress development by antioxidant and detoxification response, which are activating via transcription factor - nuclear factor erythroid 2-related factor 2 (Nrf2). Another prominent regulator of antioxidant signaling pathways that is positively associated with $\mathrm{Nrf} 2$ regulation is nuclear receptor and nutritional factor - peroxisome proliferatoractivated receptor gamma (PPAR $\gamma$ ). PPAR $\gamma$ agonists play an important role in cardiovascular diseases and hypertension (Kvandova et al. 2016).
The role of Nrf2 in hypertension and cardiovascular diseases

Nrf2 is a key transcription factor affecting antioxidant response and oxidative stress development. Functionally, Nrf2 is linked to cytoprotection in lowgrade stress, chronic inflammation, metabolic alterations, and ROS formation. Nrf2 is therefore an effective therapeutic target for chronic diseases (Cuadrado et al. 2018). It represents an innovative approach to therapeutic intervention in several cardiovascular diseases (hypertension, cardiac hypertrophy, cardiomyopathies) (Chan and Chan 2014, Barancik et al. 2016).

Pharmacologically, Nrf2 can be activated by sulforaphane, dimethyl fumarate, bardoxolone methyl and even registered drugs such as metformin and statins (Cuadrado et al. 2018). The most successful 
Nrf2 activators are the fumaric acid ester dimethyl fumarate (DMF) as well as several natural compounds designated as electrophilic Nrf2 inducers, including sulforaphane, curcumin, resveratrol, and quercetin (Robledinos-Anton et al. 2019). Sulforaphane (SFN), an isothiocyanate found in cruciferous vegetables, has been successfully used for the treatment of patients with type II diabetes mellitus (Axelsson et al. 2017). Activation of the Nrf2/ARE pathway reestablishes redox homeostasis and mediates cytoprotection against numerous pathologies by induction of cellular antioxidant and detoxification defenses (Kanninen et al. 2011, Tain et al. 2019) (Fig. 3).

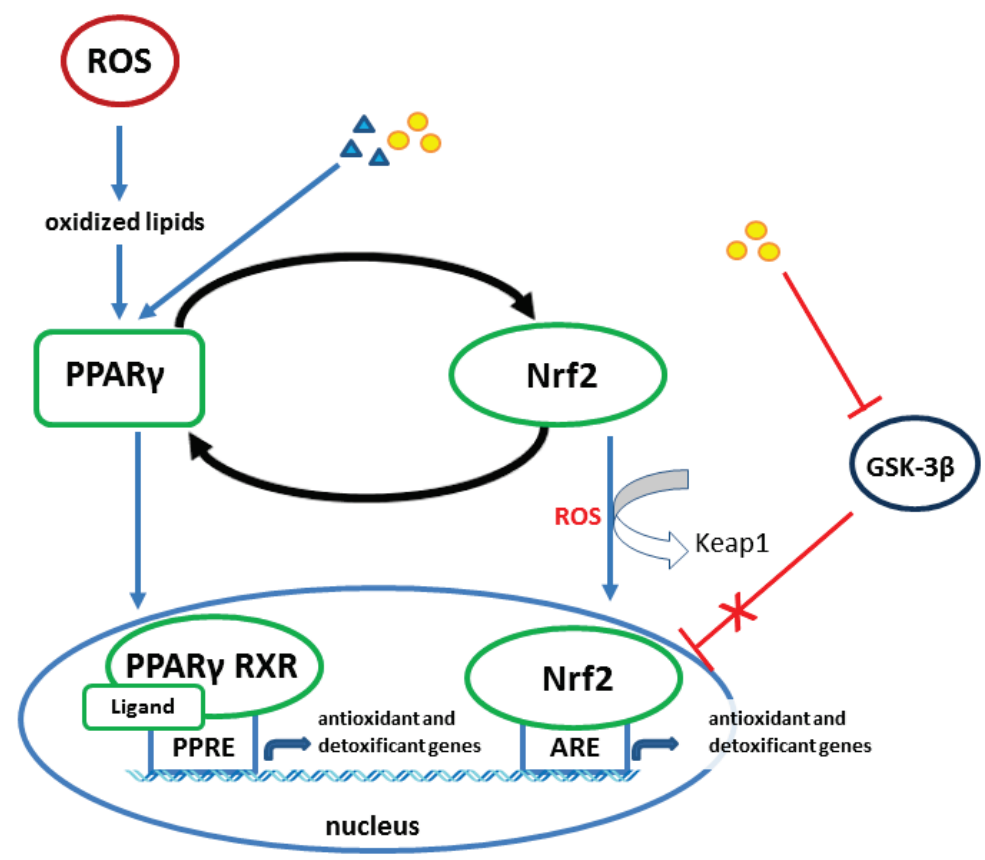

Fig. 3. Crosstalk between Nrf2 and PPARy pathways against oxidative stress.

\section{tideglusib}

\section{thiazolidinediones}

$\mathrm{Nrf} 2$ regulation is essential to maintain homeostasis of cellular function and to inhibit the progression of several pathological states including heart diseases. The cardiovascular system is mostly affected by ROS. Disturbed redox homeostasis results in increased oxidative stress and reduction of antioxidant enzymes in the heart. These disturbances are associated with poor cardiac contractility and $\mathrm{Ca}^{2+}$ instability by reduced sarco-endoplasmic reticulum $\mathrm{Ca}^{2+}$-ATPase (SERCA2a) activity (Farkhondeha et al. 2020). Calcium is a central messenger that plays important roles in cellular functions such as proliferation, contractility, protein folding, and apoptosis. $\mathrm{Ca}^{2+}$ dysregulation is associated with numerous disorders including cardiovascular and muscular diseases, and multidrug-resistant cancers (Bian et al. 2016).

$\mathrm{Nrf} 2$ is involved in redox-sensitive regulation of gene transcription and antioxidant responses and participates in radical homeostasis (Majzunova et al. 2013). Regulation of the Nrf2 $\rightarrow$ Keap $1 \rightarrow$ ARE pathway appears to depend on the duration and intensity of oxidative stress (Nguyen et al. 2009). The phosphoinositide 3-kinase /Akt kinase (PI3K/Akt), whose function is manifested in acute stress, plays an essential role in regulating the Nrf2 pathway-dependent protection (Wang et al. 2009). Activation of antioxidant and detoxificant response is the main way of eliminating ROS and is performed via activation of the Keap1-Nrf2-ARE pathway. It involves the regulation of transcription of more than 200 cytoprotective genes. Here, an important role is played by stimulation of expression of several antioxidant genes, such as superoxide dismutase (SOD), glutathione peroxidase (GPX), heme oxygenase 1 (HO-1) and the phase-II detoxification proteins - NAD $(\mathrm{P}) \mathrm{H}$ quinone dehydrogenase 1 (NQO1), glutathione-Stransferase (GST), uridine 5'-diphosphoglucuronosyltransferase (UGT) and sulfotransferases (SULT) by binding to ARE (Pall and Levine 2015, Lee 2017).

During episodes of prolonged oxidative stress, Nrf2 function is associated with the activation of 
glycogen synthase kinase $3 \beta$ (GSK-3 3 ). Activation of this enzyme during long-term oxidative stress leads, through phosphorylation of threonine residues of Fyn kinases, to downregulation of Nrf2 activity. This is associated with regulation of cytoplasmic localization and degradation of Nrf2 by ubiquitination. GSK-3 $\beta$ acts through phosphorylation of threonine residues of Fyn kinases, which then translocate into the nucleus. Fyn kinasemediated phosphorylation of $\mathrm{Nrf} 2$ at tyrosine results in export of Nrf2 out of the nucleus to cytoplasm where $\mathrm{Nrf} 2$ is exposed to degradation. This GSK-3 $\beta$-induced regulation of $\mathrm{Nrf2}$ ubiquitination and proteasome degradation is independent of Keap1 and results in a decrease or arrest of the antioxidant and detoxification response (Harrison and Gongora 2009).

Therapy by Lycopene can effectively ameliorate the oxidative stress via activation of the Nrf2/HO-1 pathway. It can recover the decreased antioxidant capacity, promote cell proliferation, inhibit apoptosis and alleviate the D-galactose-induced mitochondrial dysfunction (Liu et al. 2018).

The role of PPAR in hypertension and cardiovascular diseases

The peroxisome proliferator-activated receptor gamma - PPAR $\gamma$ - is another important ligand-dependent nuclear receptor. PPAR $\gamma$ is expressed in the adipose tissue, kidney, brain, and blood vessels, and it is activated by exogenous and endogenous agonists. PPAR $\gamma$ is strongly involved in cellular signaling. It forms a heterodimer with the retinoid X receptor (RXR), which binds to the peroxisome proliferator response element (PPRE) in the promoter region of PPAR target genes (Fig. 3) (Kvandova et al. 2016, Kvandova et al. 2018).

$\operatorname{PPAR} \gamma$ serves as a potential target in the treatment of metabolic syndrome, cardiovascular disease and hypertension (Dovinova et al. 2013, Wu et al. 2014). It can modulate several signaling pathways - the redox homeostasis signaling pathways through $\mathrm{Nrf2}$, the RAS cascade and the PI3/Akt/NOS pathway (Kvandova et al. 2016). Expression is stimulated by coactivators and corepressors with improvement of insulin sensitivity, modulated metabolism of lipids and inflammatory response. PPAR $\gamma$ improves insulin sensitivity, modulates metabolism of lipids and inflammatory response and improves blood pressure regulation: $\mathrm{PI} 3 \mathrm{~K} \rightarrow \mathrm{Akt} \rightarrow \mathrm{eNOS} \rightarrow \mathrm{NO}$ (Polvani et al. 2012).

Endothelial NO synthase (eNOS) deficiency due to endothelial cell dysfunction plays an important role in the pathophysiology of cardiovascular disease (hypertension, atherosclerosis) as well as in renal impairment (Nakagawa et al. 2011). Activation of PPAR $\gamma$ by exogenous agonists such as the thiazolidines pioglitazone and tideglusib and endogenous agonists has a potential role in blood pressure regulation in experimental models of neurogenic hypertension and metabolic syndrome (Wu et al. 2014, Kvandova et al. 2018, Armagan et al. 2019).

PPAR $\gamma$ forms a heterodimer with the retinoid $\mathrm{X}$ receptor (RXR), which binds to the peroxisome proliferator response element (PPRE) in the promoter region of PPARs target genes. RXRs are important players in the cellular regulatory machinery. They form heterodimers in the presence of several diverse nuclear receptors, playing a role of ligand-inducible transcription factors. In general, nuclear receptors are ligand-activated, transcription-modulating proteins affecting transcriptional responses in target genes. The RXRs forming permissive heterodimers with disparate nuclear receptors comprise peroxisome proliferator-activated receptors (PPARs) (Tain et al. 2016, Brtko and Dvorak 2020) (Fig. 3).

Previous results indicate that PPAR $\gamma$ is a key regulatory factor for fat differentiation, which plays a key regulatory role in the direction of differentiation in bone marrow stem cells (Roh et al. 2012). The PPAR $\gamma$ agonist pioglitazone affects hypertension, cholesterol and triglyceride levels in young spontaneously hypertensive rats (SHR) (Kvandova et al. 2018). Under oxidative stress, the PPAR $\gamma$ nuclear receptor directly regulates a number of genes involved in oxidative stress, anti-inflammatory responses and transrepression of NF- $\mathrm{KB}$. Activation of PPAR $\gamma$ by the agonists pioglitazone (PIO) or tideglusib (TDG) is associated with the Nrf2 transcription factor of redox regulation producing antioxidant and detoxification responses under oxidative stress (Tain et al. 2016, Barancik et al. 2016). In the renal signaling of young hypertensive laboratory rats, a connection between PPAR $\gamma$ and Nrf2 with antioxidant responses of superoxide dismutase (SOD1-3) was observed. Nrf2 also activated detoxification outputs (NQO1, HO-1), which improved in young borderline hypertensive rats (BHR) (Gresova et al. 2019).

Activation of PPAR $\gamma$ by the PPAR $\gamma$ agonist tideglusib works as GSK-3 $\beta$ inhibitor, affects and improves Nrf2 redox regulation, blood pressure and NO biovailability. Cardiac tissues from TDG-PPAR $\gamma$ mice with overexpressed PPAR $\gamma$ receptor, human cardiomyocytes overexpressing PPAR $\gamma$ (line AC16 cells), 
and primary cardiomyocytes treated with a PPAR $\gamma$ agonist were used to evaluate the expression of cardiac calcium regulatory proteins including sarcoplasmic reticulum $\mathrm{Ca}^{2+}$-ATPase. The expression of calcium regulatory proteins was higher in the cell lines mentioned above than in the control group (Xie et al. 2016).

Connection between Nrf2 and PPAR in hypertension and cardiovascular diseases

Activation of circulating and local reninangiotensin system components is involved in cardiovascular disorders associated with systolic and diastolic myocardial dysfunction. Increased angiotensin II production and RAS activation lead to an imbalance of redox pathways and to the activation of ROS-producing radical sources of NADPH oxidases observed in models of hypertension and metabolic syndrome (Dovinova et al. 2013, Majzunova et al. 2017, Wu et al. 2014). Oxidative stress induced by elevated levels of superoxide generated by NADPH oxidase in the brain has been shown to be associated with neurogenic hypertension (Tsai et al. 2013).

The Nrf2 transcription factor is a regulatory protein modulating redox homeostasis, with positive effect on cardiovascular system (Calabrese et al. 2012, Barancik et al. 2016, Armagan et al. 2019). It turns out that oxidative stress, depending on duration and intensity, leads to a different activation of the Keap1/Nrf2/ARE pathway (Salazar et al. 2006, Wang et al. 2008, Nguyen et al. 2009). Activation of PPAR $\gamma$ affects the regulation of neurogenic hypertension in SHR (Chan et al. 2010) and positively correlates with Nrf2 (Kvandova et al. 2016). The two transcription factors, Nrf2 and PPAR $\gamma$, have been shown to play key roles in establishing this cellular antioxidative defense system (Fig. 3). Recently, several researchers have reported ameliorating effects of pharmacological activators of Nrf2 and PPAR $\gamma$ nuclear factors on the progression of various metabolic disorders and drug-induced organ injuries by oxidative stress (Lee 2017).

\section{Improvement of cardiovascular, metabolic and hypertensive model diseases by activation of Nrf2 and PPAR $\gamma$}

Cardiovascular doxorubicin damage and quercetin therapy by Nrf2 activation

Doxorubicin (DOX) is a potent and widely used chemotherapeutic agent. It causes irreversible heart failure by increasing oxidative stress, which limits its clinical utility (Sharma et al. 2020). Doxorubicin suppresses the growth and invasiveness of tumors but triggers serious side effects in the heart and blood pressure. The onset of hypertension and heart damage were observed in Wistar rats after DOX treatment. DOX also increases superoxide levels and inhibits antioxidant activities of SOD and decreases the total antioxidant status (TAS) (Ivanova et al. 2012).

Nrf2 is a master regulator of oxidative stress signaling. It is a transcription factor that controls basal and inducible expression of antioxidant genes and other cytoprotective phase II detoxifying enzymes that are ubiquitously expressed in the cardiovascular system (Barancik et al. 2016). Quercetin is a flavonoid that possesses various biological functions including antioxidative and radical-scavenging activities. It also improves antioxidant activities of SOD. Quercetin increased Nrf2 and reduced histological abnormalities in DOX-treated animals compared to their controls. Quercetin protected against DOX-induced cardiomyopathy by increasing Nrf2 expression and thereby increasing antioxidant defense and reducing biochemical and histological abnormalities (Sharma et al. 2020). Quercetin improved blood pressure and heart function in doxorubicin-treated rats and prevents doxorubicininduced matrix metalloproteinase-2 activation and induction of apoptosis in rat hearts (Bartekova et al. 2015, Dovinova et al. 2015b).

The effect of quercetin, which reversed DOX-induced effects on blood pressure and heart rate, is shown in Figures 4A and 4B, whereas the improvement of SOD activity and SOD2 protein levels is depicted in Figures 4C and 4D.

Metabolic syndrome with hypertension and the therapy with PPAR $\gamma$ activation by the agonist pioglitazone

Hypertension is an important component of the metabolic syndrome (MetS). Recently, MetS was also associated with oxidative stress in the brain rostral ventrolateral medulla (RVLM). In RVLM, where sympathetic premotor neurons reside, the oxidative stress contributes to sympathoexcitation and hypertension ( $\mathrm{Wu}$ et al. 2014). PPAR $\gamma$ is expressed in the kidney which is involved in blood pressure control. Current experimental studies on early intervention by PPAR modulators aimed to prevent programmed hypertension and metabolic syndrome in a maternal high-fructose model. Indeed, animal studies employing a reprogramming strategy via targeting PPARs to prevent hypertension have demonstrated interesting results (Tain et al. 2015). 
A)

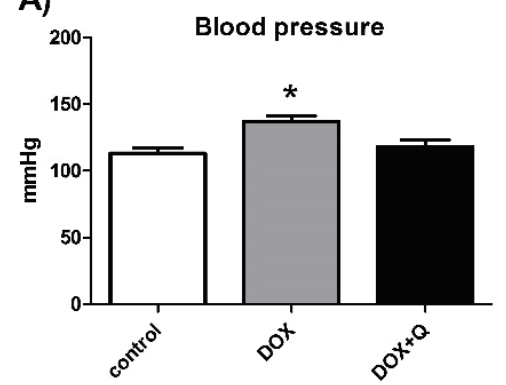

C)

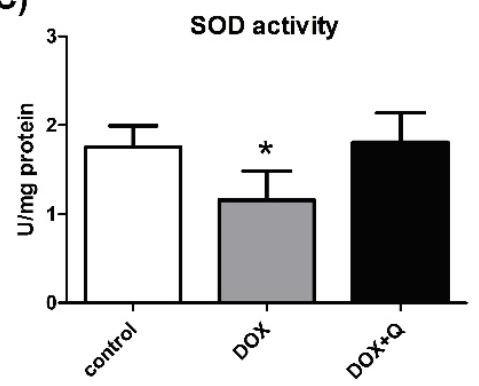

B)

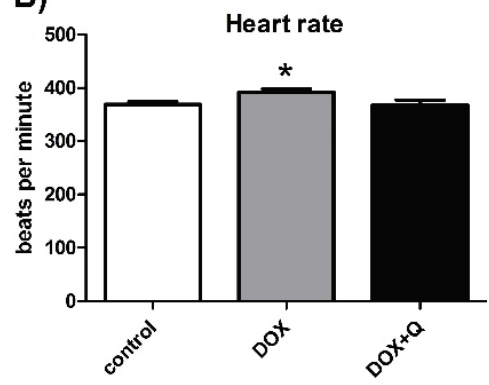

D)

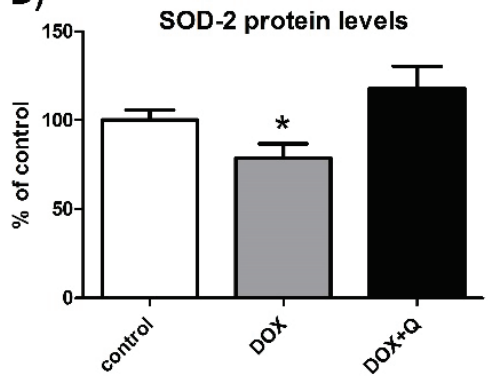

Fig. 4. Improvement of doxorubicininduced cardiovascular damage by a therapy based on Nrf2 activation by quercetin. Blood pressure (A), heart rate (B), SOD activity (C), SOD-2 protein levels (D). DOX - doxorubicin, $\mathrm{Q}$ - quercetin. Adapted from Bartekova et al. (2015) and Dovinova et al. (2015b).
In RVLM of MetS rats, the tissue level of reactive oxygen species and oxidative stress was increased, nitric oxide was decreased, and mitochondrial electron transport capacity was reduced. Protein expression of neuronal NO synthase (nNOS) or protein inhibitor of nNOS was increased, the ratio of $\mathrm{nNOS}$ dimer/monomer was significantly decreased. In RVLM of rats on high-fructose diet, blood pressure was found to increase, simulating hypertension in metabolic syndrome. Oral intake of PPAR $\gamma$ agonist pioglitazone (PIO) significantly abrogated all those molecular events in highfructose diet-fed rats and ameliorated sympathoexcitation and hypertension. Substantial decrease in mean arterial pressure was elicited by pioglitazone treatment in rats fed high-fructose diet (HFD) in which severe hypertension developed. Metabolic syndrome and hypertension deactivated nNOS in redox-sensitive nNOS uncoupling through high increase of oxidative stress in the RVLM (Wu et al. 2014).

The therapy by PPAR $\gamma$ agonist pioglitazone decreased MetS-related hypertension, improved oxidative stress and nNOS decoupling from monomer to dimer. Decreased NOS activity was restored after pioglitazone treatment (Fig. 5A-D).

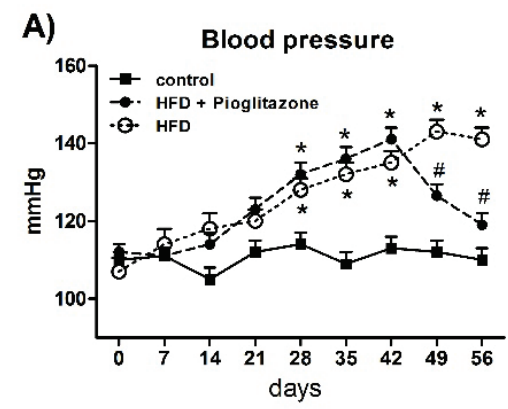

C)

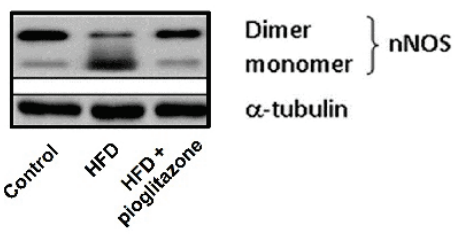

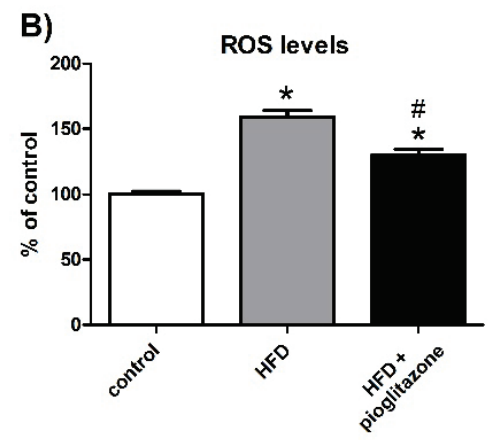

D)

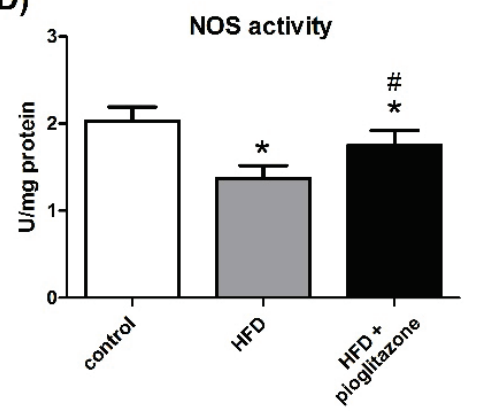

Fig. 5. Improvement of hypertension (A), oxidative stress (B), conversion of monomeric nNOS (C) and NOS activity (D) in metabolic syndrome by therapy with PPARY agonist pioglitazone (PIO). Arrow indicates the onset of PIO treatment. Control normal diet, HFD - high-fructose diet, HFD+pioglitazone - high-fructose diet and pioglitazone. Adapted from $\mathrm{Wu}$ et al. (2014). 


\section{Hypertension models with PPAR $\gamma$ and Nrf2 therapy}

The PPAR $\gamma$ receptor plays an important role in oxidative stress response. Administration of PPAR $\gamma$ agonist pioglitazone significantly slowed down blood pressure increase and improved lipid profile and aortic relaxation after insulin stimulation. An increase in PPAR $\gamma$ expression was found predominantly in the brainstem, vascular tissue and liver. The treatment with PIO differentially also affected the levels of intracellular signaling components - Akt kinase level was increased and $\beta$-catenin level was downregulated in the brainstem. The lowering of blood pressure in young SHR can be connected to insulin sensitivity of blood vessels. $\beta$-catenin and SOD levels are important agents mediating PIO effects in the brainstem and the left ventricle (Dovinova et al. 2013). Connections between PPAR $\gamma$ and Nrf2, Nrf2-activated antioxidant response (SOD1-3) and detoxificant response (NQO1, HO-1) were observed in renal signaling of young but not adult BHR (Gresova et al. 2019).

Pioglitazone treatment affected redox regulation in young hypertensive animals - BHR and SHR decreased blood pressure in BHR and slowed down the development of hypertension in young SHR. The activation by PPAR $\gamma$ correlated with increase in gene and protein expression of NOS isoforms and in total enzyme activity in both BHR and SHR.

In the AT1R/Nox pathway pioglitazone treatment did not significantly influence mRNA expression of the p22phox subunit of NADPH oxidase (Nox) and AT1R but upregulated the vasodilatory Mas and AT2R receptors in both BHR and SHR groups. Improvement of NO availability, increase of AT2R and Mas receptors, and restoration of aberrant redox regulation are thought to be the major correlated mechanisms mediating BP decrease affected by the PPAR $\gamma$ agonist treatment. In SHR pioglitazone-to-control ratio for gene expression ranged from $10 \%$ to $230 \%$. The largest effect of treatment with PPAR $\gamma$ agonist pioglitazone has been observed on the expression of SOD1, SOD3 and the Mas receptor gene. The most prominent differences between BHR and SHR were observed in SOD1 and Mas receptor expressions, with large effects of opposite sign in BHR versus SHR. Responses to PPAR $\gamma$-dependent activation of $\mathrm{Nrf} 2$ have been primarily found in the kidney of young hypertensive animals (Kvandova et al. 2018).

PPAR $\gamma$ and Nrf2 adjust blood pressure in hypertensive animals - BHR and SHR. Pioglitazone therapy also modified redox homeostasis via $\mathrm{Nrf} 2$ activation, which increased the effect of SOD and NOS activity after PPAR $\gamma$ therapy (Fig. 6A-F).

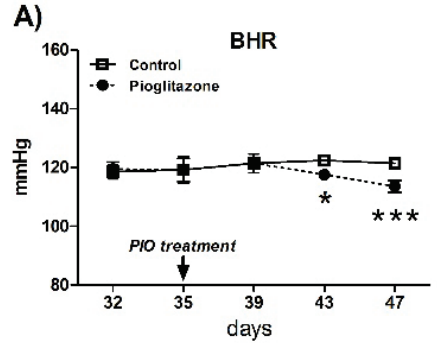

C)

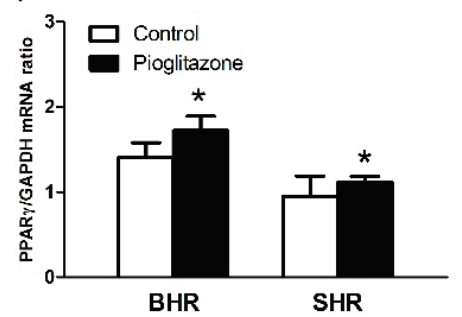

E)

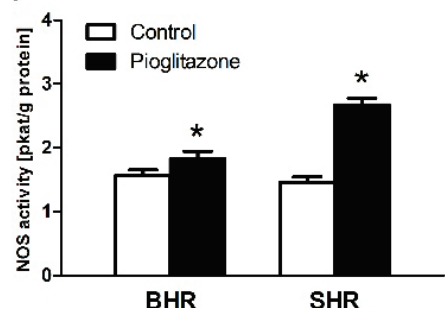

B)

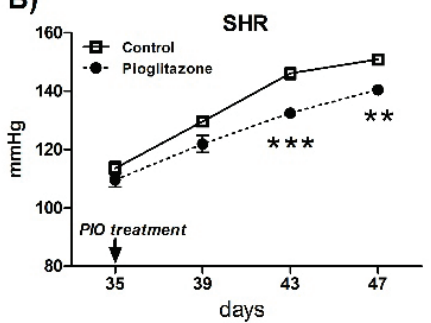

D)

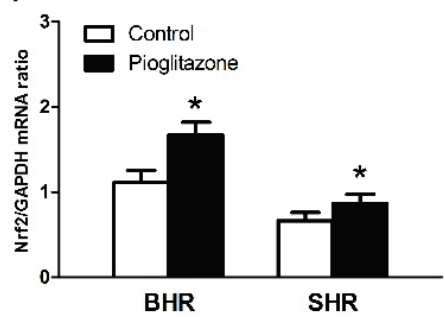

F)

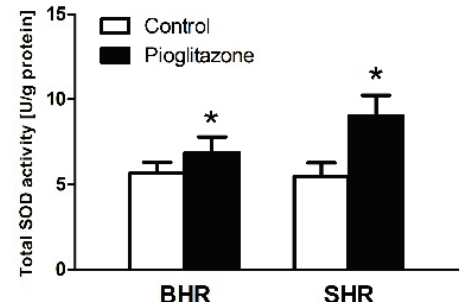

Fig. 6. Effect of pioglitazone therapy on blood pressure (A, B), on PPARy and $\mathrm{Nrf2}$ expression (C, D) and on NOS and SOD activities (E, F) as affected by PPARY and Nrf2 activation in BHR and SHR animals. Adapted from Kvandova et al. (2018). 


\section{Conclusions}

Disruption of redox homeostasis leads to aberrant cell signaling, and damage to biomolecules, which is associated with human cardiovascular pathologies. Aberrant redox regulation is a characteristic manifestation of chronic pathological changes of the myocardium and hypertension. This impaired redox balance and regulation in cardiovascular disease can be corrected by activating the
Nrf2 transcription factor and the PPAR $\gamma$ nuclear receptor.

\section{Conflict of Interest}

There is no conflict of interest.

\section{Acknowledgements}

The research behind this paper was supported by grant projects: APVV-18-0548, VEGA 2/0158/20 and VEGA 2/0190/17.

\section{References}

ANDREADOU I, SCHULZ R, PAPAPETROPOULOS A, TURAN B, YTREHUS K, FERDINANDY P, DAIBER A, DI LISA F: The role of mitochondrial reactive oxygen species, $\mathrm{NO}$ and $\mathrm{H} 2 \mathrm{~S}$ in ischemia/reperfusion injury and cardioprotection. J Cell Mol Med 24: 6510-6522, 2020. https://doi.org/10.1111/jcmm.15279

ARMAGAN G, SEVGILI E, GÜRKAN FT, KÖSE FA, BILGIÇ T, DAGCI T, SASO L: Regulation of the Nrf2 pathway by glycogen synthase kinase-3 $\beta$ in $\mathrm{MPP}^{+}$-induced cell damage. Molecules 24: 1377, 2019. https://doi.org/10.3390/molecules24071377

AXELSSON AS, TUBBS E, MECHAM B, CHACKO S, NENONEN HA, TANG Y, FAHEY JW, DERRY JMJ, WOLLHEIM CB, WIERUP N, HAYMOND MW, FRIEND SH, MULDER H, ROSENGREN AH: Sulforaphane reduces hepatic glucose production and improves glucose control in patients with type 2 diabetes. Sci Transl Med 9: eaah4477, 2017. https://doi.org/10.1126/scitranslmed.aah4477

BALAKUMAR P, JAGADEESH G: Multifarious molecular signaling cascades of cardiac hypertrophy: can the muddy waters be cleared. Pharmacol Res 62: 365-383, 2010. https://doi.org/10.1016/j.phrs.2010.07.003

BARANČÍK M, GREŠOVÁ L, BARTEKOVÁ M, DOVINOVÁ I: Nrf2 as a key player of redox regulation in cardiovascular diseases. Physiol Res 65 (Suppl 1): S1-S10, 2016. https://doi.org/10.33549/physiolres.933403

BARTEKOVÁ M, ŠIMONČÍKOVA P, FOGARASSYOVÁ M, IVANOVÁ M, OKRUHLICOVÁ L, TRIBULOVÁ N, DOVINOVÁ I, BARANČÍK M: Quercetin improves postischemic recovery of heart function in doxorubicintreated rats and prevents doxorubicin-induced matrix metalloproteinase-2 activation and apoptosis induction. Int J Mol Sci 16: 8168-8185, 2015. https://doi.org/10.3390/ijms16048168

BIAN T, AUTRY JM, CASEMORE D, LI J, THOMAS DD, HE G, XING C: Direct detection of SERCA calcium transport and small-molecule inhibition in giant unilamellar vesicles. Biochem Biophys Res Commun 481: 206-211, 2016. https://doi.org/10.1016/j.bbrc.2016.10.096

BRTKO J, DVORAK Z: Natural and synthetic retinoid X receptor ligands and their role in selected nuclear receptor action. Biochimie 179: 157-168, 2020. https://doi.org/10.1016/j.biochi.2020.09.027

CALABRESE V, CORNELIUS C, DINKOVA-KOSTOVA AT, IAVICOLI I, DI PAOLA R, KOVERECH A, CUZZOCREA S, RIZZARELLI E, CALABRESE EJ: Cellular stress responses, hormetic phytochemicals and vitagenes in aging and longevity. Biochim Biophys Acta 1822: 753-783, 2012. https://doi.org/10.1016/j.bbadis.2011.11.002

CHAN SH, WU KL, KUNG PS, CHAN JY: Oral intake of rosiglitazone promotes a central antihypertensive effect via upregulation of peroxisome proliferator-activated receptor-gamma and alleviation of oxidative stress in rostral ventrolateral medulla of spontaneously hypertensive rats. Hypertension 55: 1444-1453, 2010. https://doi.org/10.1161/HYPERTENSIONAHA.109.149146

CHAN SH, CHAN JY: Brain stem NOS and ROS in neural mechanisms of hypertension. Antioxid Redox Signal 20: 146-163, 2014. https://doi.org/10.1089/ars.2013.5230

CRABTREE MJ, CHANNON KM: Synthesis and recycling of tetrahydrobiopterin in endothelial function and vascular disease. Nitric Oxide 25: 81-88, 2011. https://doi.org/10.1016/j.niox.2011.04.004 
CUADRADO A, MANDA G, HASSAN A, ALCARAZ MJ, BARBAS C, DAIBER A, GHEZZI P, LEÓN R, LÓPEZ MG, OLIVA B, PAJARES M, ROJO AI, ROBLEDINOS-ANTÓN N, VALVERDE AM, GUNEY E, SCHMIDT HHHW: Transcription factor NRF2 as a therapeutic target for chronic diseases: a systems medicine approach. Pharmacol Rev 70: 348-383, 2018. https://doi.org/10.1124/pr.117.014753

DOVINOVA I, GARDLIK R, PALFFY R, KRISTEK F, CACANYIOVA S, VANTOVA Z, PAULIKOVA H: Modulation of antioxidative response in the therapy of hypertension and other cardiovascular diseases. Neuro Endocrinol Lett 30 (Suppl 1): 32-35, 2009.

DOVINOVA I, BARANCIK M, MAJZUNOVA M, ZORAD S, GAJDOSECHOVA L, GRESOVÁ L, CACANYIOVA S, KRISTEK F, BALIS P, CHAN JY: Effects of PPAR $\gamma$ agonist pioglitazone on redox-sensitive cellular signaling in young spontaneously hypertensive rats. PPAR Res 2013: 541871, 2013. https://doi.org/10.1155/2013/541871

DOVINOVÁ I, MAJZÚNOVÁ M: Regulation mechanisms in hypertension pathophysiology: Aberrant redox regulation in hypertension. In: Regulation Mechanisms in the Pathophysiology of Hypertension. (In Slovak) KRISTEK F, CACANYIOVA S, TOROK J (eds), Institute of normal and pathological physiology, Slovak Academy of sciences, Bratislava, 2015a, pp 103-116.

DOVINOVA I, BARANCIK M, KRATKA D, FOGARASSYOVA M, KVANDOVA M, BARTEKOVA M: Pathological changes in cardiovascular system in long-term doxorubicin-treated rats and effect of quercetin. Cardiol Lett 24: 243-246, 2015 b.

FARKHONDEHA T, FOLGADOB SL, POURBAGHER-SHAHRIC AM, ASHRAFIZADEHD M, SAMARGHANDIANE S: The therapeutic effect of resveratrol: Focusing on the Nrf2 signaling pathway. Biomed Pharmacother 127: 110234, 2020. https://doi.org/10.1016/j.biopha.2020.110234

FINKEL T: Signal transduction by reactive oxygen species. J Cell Biol 194: 7-15, 2011. https://doi.org/10.1083/jcb.201102095

GRESOVA L, KVANDOVA M, KVASNICKA P, DOVINOVA I: Age-dependent effect of PPAR $\gamma$ agonist pioglitazone on kidney signaling in borderline hypertensive rats. Gen Physiol Biophys 38: 259-264, 2019. https://doi.org/10.4149/gpb 2019005

HARRISON DG, GONGORA MC: Oxidative stress and hypertension. Med Clin North Am 93: 621-635, 2009. https://doi.org/10.1016/j.mcna.2009.02.015

IVANOVA M, DOVINOVA I,OKRUHLICOVA L, TRIBULOVA N,SIMONCIKOVA P, BARTEKOVA M, VLKOVICOVA J, BARANCIK M: Chronic cardiotoxicity of doxorubicin involves activation of myocardial and circulating matrix metalloproteinases in rats. Acta Pharmacol Sin 33: 459-469, 2012. https://doi.org/10.1038/aps.2011.194

KANNINEN K, WHITE AR, KOISTINAHO J, MALM T: Targeting glycogen synthase kinase-3 $\beta$ for therapeutic benefit against oxidative stress in Alzheimer's disease: involvement of the Nrf2-ARE pathway. Int J Alzheimers Dis 2011: 985085, 2011. https://doi.org/10.4061/2011/985085

KVANDOVA M, MAJZUNOVA M, DOVINOVA I: The role of PPARgamma in cardiovascular diseases. Physiol Res 65 (Suppl 3): S343-S363, 2016. https://doi.org/10.33549/physiolres.933439

KVANDOVA M, BARANCIK M, BALIS P, PUZSEROVA A, MAJZUNOVA M, DOVINOVA I: The peroxisome proliferator-activated receptor gamma agonist pioglitazone improves nitric oxide availability, renin-angiotensin system and aberrant redox regulation in the kidney of pre-hypertensive rats. J Physiol Pharmacol 69: 231-243, 2018. https://doi.org/10.26402/jpp.2018.2.09

LEE CH: Collaborative power of Nrf2 and PPAR $\gamma$ activators against metabolic and drug-induced oxidative injury. Oxid Med Cell Longev 2017: 1378175, 2017. https://doi.org/10.1155/2017/1378175

LIU X, LIN X, ZHANG S, GUO CH, LI J, MI Y, ZHANG C: Lycopene ameliorates oxidative stress in the aging chicken ovary via activation of Nrf2/HO-1 pathway. Aging 10: 2016-2036, 2018. https://doi.org/10.18632/aging.101526

MAJZUNOVA M, DOVINOVA I, BARANCIK M, CHAN JYH: Redox signaling in pathophysiology of hypertension. J Biomed Sci 20: 69-78, 2013. https://doi.org/10.1186/1423-0127-20-69

MAJZUNOVA M, PAKANOVA Z, KVASNICKA P, BALIS P, CACANYIOVA S, DOVINOVA I: Age-dependent redox status in the brain stem of NO-deficient hypertensive rats J Biomed Sci 24: 72, 2017. https://doi.org/10.1186/s12929-017-0366-4 
NAKAGAWA T, TANABE K, CROKER BP, JOHNSON RJ, GRANT MB, KOSUGI T, LI Q: Endothelial dysfunction as a potential contributor in diabetic nephropathy. Nat Rev Nephrol 7: 36-44, 2011. https://doi.org/10.1038/nrneph.2010.152

NGUYEN T, NIOI P, PICKETT CB: The Nrf2-antioxidant response element signaling pathway and its activation by oxidative stress. J Biol Chem 284: 13291-13295, 2009. https://doi.org/10.1074/jbc.R900010200

PALL ML, LEVINE S: Nrf2, a master regulator of detoxification and also antioxidant, anti-inflammatory and other cytoprotective mechanisms, is raised by health promoting factors. Acta Physiol Sin 67: 1-18, 2015.

POLVANI S, TAROCCHI M, GALLI A: PPAR $\gamma$ and oxidative stress: Con $(\beta)$ catenating NRF2 and FOXO. PPAR Res 2012: 641087, 2012. https://doi.org/10.1155/2012/641087

ROBLEDINOS-ANTÓN M, FERNÁNDEZ-GINÉS R, MANDA G, CUADRADO A: Activators and inhibitors of NRF2: a review of their potential for clinical development. Oxid Med Cell Long 2019: 9372182, 2019. https://doi.org/10.1155/2019/9372182

ROH JH, HUANG Y, BERO AW, KASTEN T, STEWART FR, BATEMAN RJ, HOLTZMAN DM: Disruption of sleep wake cycle and diurnal fluctuation of $\beta$ amyloid in mice with Alzheimer's disease pathology. Sci Transl Med 4: 150ra122, 2012. https://doi.org/10.1126/scitranslmed.3004291

SALAZAR M, ROJO AI, VELASCO D, DE SAGARRA RM, CUADRADO A: Glycogen synthase kinase-3beta inhibits the xenobiotic and antioxidant cell response by direct phosphorylation and nuclear exclusion of the transcription factor Nrf2. J Biol Chem 281: 14841-14851, 2006. https://doi.org/10.1074/jbc.M513737200

SCHIEBER M, CHANDEL NS: ROS function in redox signaling and oxidative stress. Curr Biol 24: R453-R462, 2014. https://doi.org/10.1016/j.cub.2014.03.034

SHARMA A, PARIKH M, SHAH H, GANDHI T: Modulation of Nrf2 by quercetin in doxorubicin-treated rats. Heliyon 6: e03803, 2020. https://doi.org/10.1016/j.heliyon.2020.e03803

SIES H, JONES DP: Reactive oxygen species (ROS) as pleiotropic physiological signalling agents. Nat Rev Mol Cell Biol 21: 363-383, 2020. https://doi.org/10.1038/s41580-020-0230-3

SIES H, BERNDT C, JONES DP: Oxidative stress. Annu Rev Biochem 86: 715-748, 2017. https://doi.org/10.1146/annurev-biochem-061516-045037

TAIN YL, HSU CHN, CHAN JY: PPARs link early life nutritional insults to later programmed hypertension and metabolic syndrome. Int J Mol Sci 17: 20, 2015. https://doi.org/10.3390/ijms17010020

TIAN Y, WANG W, XU L, LI H, WEI Y, WU Q, JIA J: Activation of Nrf2/ARE pathway alleviates the cognitive deficits in PS1V97L-Tg mouse model of Alzheimer's disease through modulation of oxidative stress. J Neurosci Res 97: 492-505, 2018. https://doi.org/10.1002/jnr.24357

TOUYZ RM: Molecular and cellular mechanisms in vascular injury in hypertension: role of angiotensin II. Curr Opin Nephrol Hypertens 14: 125-131, 2005. https://doi.org/10.1097/00041552-200503000-00007

TSAI CY, SU CH, BAUDRIE V, LAUDE D, WENG JCH, CHANG AY, CHAN JY, ELGHOZI JL, CHAN SH: Visualizing oxidative stress-induced depression of cardiac vagal baroreflex by MRI/DTI in a mouse neurogenic hypertension model. Neuroimage 82: 190-199, 2013. https://doi.org/10.1016/j.neuroimage.2013.05.124

USHIO-FUKAI M: Vascular signaling through G protein-coupled receptors: new concepts. Curr Opin Nephrol Hypertens 18: 153-159, 2009. https://doi.org/10.1097/MNH.0b013e3283252efe

WANG L, CHEN Y, STERNBERG P, CAI J: Essential roles of the PI3 kinase/Akt pathway in regulating Nrf2-dependent antioxidant functions in the RPE. Invest Ophthalmol Vis Sci 49: 1671-1678, 2008. https://doi.org/10.1167/iovs.07-1099

WANG SY, JIAO H: Scavenging capacity of berry crops on superoxide radicals, hydrogen peroxide, hydroxyl radicals, and singlet oxygen. J Agric Food Chem 48: 5677-5684, 2000. https://doi.org/10.1021/jf000766i

WANG Y, BRANICKY R, NOË A, HEKIMI S: Superoxide dismutases: Dual roles in controlling ROS damage and regulating ROS signaling. J Cell Biol 217: 1915-1928, 2018. https://doi.org/10.1083/jcb.201708007

WU KL, WU CA, WU CW, CHAN SH, CHAMG AY, CHAN JY: Redox-sensitive oxidation and phosphorylation of PTEN contribute to enhanced activation of PI3K/Akt signaling in rostral ventrolateral medulla and neurogenic hypertension in spontaneously hypertensive rats. Antioxid Redox Signal 18: 36-50, 2013. https://doi.org/10.1089/ars.2011.4457 
WU KL, CHAO YM, TSAY SJ, CHEN CH, CHAN SH, DOVINOVA I, CHAN JY: Role of nitric oxide synthase uncoupling at rostral ventrolateral medulla in redox-sensitive hypertension associated with metabolic syndrome Hypertension 64: 815-824, 2014. https://doi.org/10.1161/HYPERTENSIONAHA.114.03777

XIE Y, GU ZJ, WU MX, HUANTC, OU JS, NI HS, LIN MH, YUAN WL, WANG JF: Disruption of calcium homeostasis by cardiac-specific over-expression of PPAR- $\gamma$ in mice: A role in ventricular arrhythmia. Life Sci 167: 12-21, 2016. https://doi.org/10.1016/j.1fs.2016.10.014 